\title{
Soluções de Equações Quadráticas por 'Abd Al-Hamid lbn Turk na Formação Inicial do Professor de Matemática
}

\author{
Giselle Costa de Sousa \\ Jéssica Targino Muniz
}

\begin{abstract}
Resumo: Esse trabalho deriva-se de uma pesquisa de mestrado profissional desenvolvida no Programa de PósGraduação em Ensino de Ciências Naturais e Matemática (PPGECNM), ligado à Universidade Federal do Rio Grande do Norte (UFRN). Esse estudo qualitativo almeja a aliança entre a história da matemática e as tecnologias digitais de informação e comunicação via investigação matemática para abordagem de álgebra geométrica na licenciatura em matemática. Para isso, baseado em Miguel e Miorim (2011), Ponte, Brocardo e Oliveira (2013) e Borba e Penteado (2017), foi elaborado e aplicado um caderno de atividades que trata da solução de equações quadráticas sob ótica de Abd Al-Hamid Ibn Turk, matemático islâmico do século IX. Para coletar dados foram utilizados registros de alunos, diário de campo, entre outros. Os resultados mostraram ampliação do repertório intelectual dos licenciandos.
\end{abstract}

Palavras-chave: Equações Quadráticas. Formação Docente. História da Matemática. Tecnologias Digitais. Investigação Matemática.

\section{Quadratic Equations Solutions by 'Abd Al-Hamid Ibn Turk in the Initial Training of the Mathematics Teacher \\ Giselle Costa de Sousa} Doutora em Educação pela Universidade Federal do Rio Grande do Norte (UFRN), campus Natal. Professora do PPGECNM (UFRN), Natal, RN, Brasil. https://orcid.org/0000-0003-0213-

$\triangle$ gisellematufrn@gmail.com

Jéssica Targino Muniz Mestre em Ensino de Ciências Naturais e Matemática pela Universidade Federal do Rio Grande do Norte (UFRN), campus Natal. Professora de Matemática (CEDAP), Santa Cruz, RN, Brasil. Dhtps://orcid.org/0000-0001-9999-

$\underline{3492}$

$\triangle$ jessica.tar@hotmail.com

Recebido em 14/01/2021 Aceito em 11/02/2021

Publicado em 24/02/2021
Abstract: This work derives from a professional master's research developed in the Graduate Program in Education of Natural Sciences and Mathematics (PPGECNM), linked to the Federal University of Rio Grande do Norte(UFRN). This qualitative study aims at the alliance between the history of mathematics and digital information and communication technologies through mathematical investigation for the approach of geometric algebra in the mathematics degree. To this end, based on Miguel and Miorim (2011), Ponte, Brocardo and Oliveira (2013) and Borba and Penteado (2017), an activity book was prepared and applied that deals with solving quadratic equations from the eyesight of Abd Al- Hamid Ibn Turk, Islamic mathematician of the 9th century. Student data, field diary, among others, were used to collect data. The results showed an enrichment of the intellectual background of the graduates.

Keywords: Quadratic Equations. Teacher Training. History of Mathematics. Digital Technologies. Mathematical Research.

\section{Soluciones de Ecuaciones Cuadráticas de 'Abd Al-} Hamid Ibn Turk en la Formación Inicial de Profesores de Matemáticas

Resumen: Este trabajo se deriva de una investigación de maestría profesional desarrollada en el Programa de Posgrado en Educación de Ciencias Naturales y Matemáticas (PPGECNM), vinculado a la Universidad Federal do Rio Grande do Norte (UFRN). Este estudio cualitativo tiene como objetivo la integración entre la historia de las matemáticas y las tecnologías de la información y la comunicación digitales a través de la investigación matemática para la enseñanza del álgebra geométrica en la carrera de matemáticas. Para ello, a partir de Miguel y Miorim (2011), Ponte, Brocardo y Oliveira (2013) y Borba y Penteado (2017), se elaboró y aplicó un libro de actividades que trata sobre la resolución de ecuaciones cuadráticas desde la vista de Abd Al- Hamid lbn Turk, matemático islámico del siglo IX. Se utilizaron datos de estudiantes, diario de campo, entre otros, para recolectar datos. Los resultados mostraron un enriquecimiento de la formación intelectual de los graduados.

Palabras clave: Ecuaciones Cuadráticas. Formación de Profesores. Historia de las Matemáticas. Tecnologías Digitales. Investigación Matemática. 


\section{Introdução}

Esse artigo se deriva de um estudo de mestrado profissional desenvolvido no Programa de PósGraduação em Ensino de Ciências Naturais e Matemática (PPGECNM), ligado à Universidade Federal do Rio Grande do Norte (UFRN). A questão que norteou a referida pesquisa foi a seguinte: De que maneira seria possível aliar história da matemática $(H M)$ e tecnologias digitais da informação e comunicação (TDIC) via investigação matemática (IM) para o estudo e/ou ensino de álgebra geométrica na licenciatura em matemática? Sua resposta é apresentada do decorrer do presente texto, revelando a procura pela reflexão e a socialização de conhecimento sobre os processos de ensino e de aprendizagem da matemática.

Para responder tal pergunta, foi realizada uma pesquisa qualitativa de cunho bibliográfico a procura de um assunto da história da matemática que pudesse ser utilizado como guia na elaboração/aplicação de atividades e situações-problema (MIGUEL; MIORIM, 2011). Como resultado, a temática escolhida foi a resolução de equações quadráticas na visão do islâmico 'Abd Al-Hamid Ibn Turk, que viveu por volta do século IX. Ibn Turk utilizou-se de um entendimento geométrico buscando soluções para equações polinomiais de $2^{\circ}$ grau mediante constituição de figuras que representassem essas equações.

Ao realizar o estudo bibliográfico e delinear o conteúdo a ser tratado, foram propostas atividades para os licenciandos usando o software GeoGebra, considerando que é um recurso que oferece várias características que favoreceram o trabalho a ser desenvolvido: software gratuito, interface intuitiva e ferramentas variadas que permitem experimentações com dinamicidade para as investigações. Nesse processo, adotou-se a investigação matemática como uma proposta que guiaria as atividades. Isso para propiciar, aos futuros professores, a (re)descoberta e apreciação da maneira pela qual Ibn Turk tratou equações quadráticas, de forma que eles atuassem na investigação pelo conhecimento frente ao contexto desse estudioso islâmico. Assim sendo, o alvo dessa pesquisa foi desenvolver um estudo histórico bibliográfico sobre álgebra geométrica com referência ao trabalho de lbn Turk e, a partir disto, indicar um produto educacional regulado no uso da história da matemática aliado às TDIC via investigação matemática para futuros professores de matemática, promovendo, na formação docente, ponderações sobre as tendências antes citadas e uma outra argúcia sobre equações quadráticas.

Para chegar ao desígnio revelado anteriormente, foi elaborada uma pesquisa de cunho qualitativo, apontando, portanto, a investigação e apreciação do comportamento, das ideias e das percepções dos envolvidos na mesma, considerando o entendimento global do contexto daqueles que estão vivendo o fenômeno observado (POLIT; BECK; HUNGLER, 2004). Bogdan e Biklen (1994) defendem que a pesquisa qualitativa possui cinco características básicas, são elas: a fonte direta dos 
dados é o ambiente natural, dessa forma, o investigador é o instrumento principal, em nossa pesquisa, a sala de aula foi o ambiente e as autoras desse artigo, as investigadoras; os dados coletados são descritivos, sendo analisados de forma minuciosa. Nesse estudo, o recolhimento de dados ocorreu através de diário de campo, foto e filmagem, registros escritos e virtuais de discentes e de questionários inicial e final. Outro aspecto de pesquisa dessa natureza é que o pesquisador busca analisar esses dados em toda sua complexidade, respeitando ao máximo o modo como foram registrados ou transcritos; e ainda o interesse maior na pesquisa está no processo e não no resultado. Finalmente, enfatiza-se que há uma tendência em analisar os dados de forma indutiva e o sentido é de suma importância nessa categoria de abordagem. Dessa forma, considerando a ótica do informante, atribui-se importância à interpretação, à realidade, ao contexto e à visão de mundo dos sujeitos envolvidos na pesquisa de maneira mais fiel possivel.

Desse modo, as etapas da pesquisa ocorreram assim: primeiramente, foi efetivado um exame bibliográfico para o desígnio e aperfeiçoamento do tema histórico a ser tratado, ou seja, o capítulo Necessidades Lógicas em Equações Mistas, única parte disponível da produção Kitâb Al Jabr Wa’l Muqâbala feita por 'Abd Al-Hamid Ibn Turk. Para mais, foram ainda estudadas as tendências em Educação Matemática: história da matemática, tecnologias digitais de informação e comunicação e investigação matemática, para constituir o referencial teórico dessa pesquisa.

$\mathrm{Na}$ fase ulterior dessa pesquisa, foi elaborado e aplicado o caderno de atividades (produto educacional), elaborado com apoio do uso da história da matemática coligada as TDIC via investigação matemática, considerando como público estudantes de licenciatura em matemática e âmago na álgebra geométrica sugerida por Ibn Turk de modo a culminar numa proposta de formação de professores de matemática. Assim sendo, essa fase do estudo tem elementos da pesquisa-ação, sendo que a constituição de uma sequência de atividades históricas compõe sua primeira fase; e a aplicação do caderno de atividades, concretizada em uma turma de Didática da Matemática I do curso de licenciatura em matemática da UFRN, compõe a segunda etapa da pesquisa-ação.

Conforme Tripp (2005, p. 447), pesquisa-ação "é uma forma de investigação-ação que utiliza técnicas de pesquisa consagradas para informar a ação que se decide tomar para melhorar a prática". Thiollent (1988, p. 14) assinala que esse tipo de pesquisa:

é concebida e realizada em estreita associação com uma ação ou com a resolução de um problema coletivo e no qual os pesquisadores e os participantes representativos da situação da realidade a ser investigada estão envolvidos de modo cooperativo e participativo. 
Assim, foi elaborado e aplicado um caderno de atividades com estudantes da licenciatura em matemática, de modo a expandir a formação docente, sendo as investigadoras, a docente da turma em que foi feita a intervenção e a mestranda que, na ocasião, fez docência assistida na turma. Enfatiza-se ainda que a aplicação do produto educacional foi feita de maneira a propiciar o aprimoramento do mesmo, baseado na compreensão dos eventos ocorridos/dados coletados em meio a execução das atividades. Frente a essa apreciação preliminar do trabalho, seguimos com aspectos de fundamentação do mesmo.

\title{
2 A história da matemática aliada às tecnologias digitais da informação e comunicação via investigação matemática
}

O alicerce que fundamenta o desdobramento dessa pesquisa é a aliança entre as tendências da Educação Matemática supracitadas. Realmente, o caderno de atividades (produto educacional para formação de professores) foi elaborado para que os professores em formação realizassem investigações históricas envolvendo o estudo do procedimento de resolução de equações quadráticas por Ibn Turk, com amparo do software GeoGebra.

Dessa forma, avulta-se que a história da matemática, ao ser utilizada como um guia na preparação de atividades, no exame e fonte de situações-problema e na procura de referências e métodos para melhor clarificar conceitos matemáticos (MIGUEL e MIORIM, 2011), colabora para que os alunos enxerguem a matemática como uma ciência que se produz historicamente em diversos sentidos. Assim, almeja-se que percebam que a informação matemática versa sobre objetos culturais elaborados e usados em cada etapa do desdobramento das sociedades no planeta, no decorrer dos anos, e não como um encadeamento de representações de algoritmos, fórmulas, teoremas e definições sem sentido e/ou linear e progressista.

Roque (2012) pondera que:

\begin{abstract}
Um dos fatores que contribuem para que a matemática seja considerada abstrata reside na forma como a disciplina é ensinada, fazendo-se uso, muitas vezes, da mesma ordem de exposição presente nos textos matemáticos. Ou seja, em vez de partirmos do modo como um conceito matemático foi desenvolvido, mostrando as perguntas às quais ele responde, tomamos esse conceito como algo pronto. (ROQUE, 2012, p. 20)
\end{abstract}

Nesse cenário, o procedimento construtivo da matemática por gerações antecedentes à nossa, quando tratado em sala de aula, ajuda o discente a entender o desenvolvimento dessa ciência em cada período histórico, além de pensar sobre a formalização de leis matemáticas e colocar a matemática como manifestação cultural. 
Em conformidade com esse aspecto, Mendes, Fossa e Valdés (2006) assinalam que a história é uma maneira de responder às indagações sobre o procedimento de constituição das informações proporcionadas no presente. Ela pode também ser empregada como instrumento mediador na confecção de novos modos para compreensão e elucidação de acontecimentos históricos, à medida que a sociedade se altera e os vê de outra forma. Logo, a história gera nos estudantes um posicionamento crítico diante da própria história, permitindo (re)leituras e ponderações para eventos históricos.

Sobre o uso da história da matemática na formação inicial do professor de matemática, Fauvel e Maanen (2000) enfatizam como funções principais:

\footnotetext{
i) levar os futuros professores a conhecer a matemática do passado (função direta da História da Matemática)

ii) melhorar a compreensão da matemática que eles irão ensinar (funções metodológicas e epistemológicas)

iii) fornecer métodos e técnicas para incorporar materiais históricos em sua prática (o uso da História da Matemática em sala de aula)

iv) ampliar o entendimento do desenvolvimento do currículo e de sua profissão (a História do ensino da matemática) (FAUVEL; MAANEN, 2000, p. 110).
}

Nessa pesquisa, problemas/situações históricas (contexto islâmico medieval e atual) foram investigadas pelos licenciandos com suporte do software GeoGebra, provocando diversas discussões sobre a HM, TDIC e IM na Educação Matemática, colaborando, nesse aspecto, para a formação docente, bem como trazendo para os licenciandos uma outra argúcia sobre equações quadráticas. Para Mendes (2006),

Os estudantes podem vivenciar experiências manipulativas resgatadas das informações
históricas, com vistas a desenvolver o seu espírito investigativo, sua curiosidade científica e
suas habilidades matemáticas, de modo a alcançar sua autonomia intelectual, principalmente
por percebermos que atualmente a escola está deixando cada vez mais de lado esses
aspectos indispensáveis para uma educação integral e formadora de cidadãos pensantes.
(MENDES, 2006, p. 87)

Relativo à história da matemática, a adoção da perspectiva pedagógica que a utilize como fonte geradora de conhecimento matemático escolar remete à investigação matemática, mais particularmente, à investigação histórica. Essa, por sua vez, deve ser encarada como uma sugestão que promove a problematização de situações advindas no decorrer da história da matemática. Assim, em uma investigação matemática, particularmente, na investigação de um problema histórico e/ou inspirado na história da matemática, o estudante é chamado a explorar perguntas para as quais não se tem resposta aprontada, buscando, por meio do levantamento e validação de conjecturas, respostas e explicações para resolver tal problema.

Conforme Roque (2012), com a história da matemática, 
Podemos, então, analisar o momento no qual os conceitos foram criados e como os resultados, que hoje consideramos clássicos, foram demonstrados, contrabalançando a concepção tradicional que se tem da matemática como um saber operacional, técnico ou abstrato. $\mathrm{A}$ história da matemática pode perfeitamente tirar do esconderijo os problemas que constituem o campo de experiência do matemático, ou seja, o lado concreto do seu fazer, a fim de que possamos entender melhor o sentido de seus conceitos. (ROQUE, 2012, p. 23)

Destaca-se que a inquirição de resolução de algum problema (particularmente, inspirado na história da matemática) por meio da investigação matemática demanda a efetivação de diversas etapas, que podem acontecer ao mesmo tempo ou também ciclicamente. Essas fases estão no caderno de atividades, bem como na aplicação dele na formação inicial do professor de matemática. Ponte, Brocardo e Oliveira (2013) nomeiam essas etapas de momentos, sintetizando-as no quadro adiante:

Quadro 1: Momentos na efetivação de uma investigação

\begin{tabular}{|r|ll|}
\hline Exploração e formulação de & $\bullet$ & Reconhecer uma situação problemática \\
questões & $\bullet$ & Explorar a situação problemática \\
& $\bullet$ & Formular questões \\
\hline Conjecturas & $\bullet$ & Organizar dados \\
& - & Formular conjecturas (e fazer afirmações sobre uma \\
& conjectura) \\
\hline Testes e reformulação & $\bullet$ & Realizar testes \\
& $\bullet$ & Refinar uma conjectura \\
\hline Justificação e Avaliação & $\bullet$ & Justificar uma Conjectura \\
& $\bullet$ & Avaliar o raciocínio ou resultado do raciocínio \\
\hline
\end{tabular}

Fonte: PONTE, BROCARDO e OLIVEIRA (2013, p. 21)

Percebe-se que esses momentos ficam intimamente ligados ao trabalho produzido ao longo da história da matemática (apesar dos vários avanços, recuos e descontinuidades), para a própria constituição da matemática. Destarte, a abordagem da matemática sob uma conjuntura histórica da matemática-investigação ocorre através da problematização de circunstâncias da história da matemática que recaem na (re)descoberta e incremento de conclusões, particularmente relacionadas à investigação de solução de equações quadráticas por meio de raciocínio geométrico. Conforme Mendes (2006):

[...] uma abordagem didática investigatória nas aulas de matemática, apoiada nas informações históricas, pode contribuir na concretização de um ensino e aprendizagem da matemática com significado, ao envolver situações históricas problematizadoras que conduzam os estudantes em busca de sua aprendizagem matemática. (MENDES, 2006, p. 67). 
O caderno de atividades, desenvolvido sob o referencial apresentado, almeja que os licenciandos enxerguem a matemática como fruto de processos históricos constituindo uma relação passado-presente respeitando os diferentes contextos, por meio do desenvolvimento de conhecimentos matemáticos relacionados às equações quadráticas tendo em vista seu contexto. Nessa perspectiva, o software GeoGebra se constitui ambiente favorável para que os alunos realizem a exploração de problemas que envolvem resoluções de equações quadráticas a partir da álgebra geométrica de Ibn Turk.

Nas verificações de Ponte, Brocardo e Oliveira (2013), o apoio tecnológico admite o desenho, a manipulação e a construção de entes matemáticos, provoca a exploração de conjecturas e a investigação de relações que antecedem o uso do raciocínio formal, o que colabora com os juízos da investigação matemática exibidas nessa pesquisa. Os autores destacam também que o emprego dessas tecnologias facilita a coleta de dados e 0 teste de conjecturas, amparando, assim, explorações mais organizadas e completas e admitindo que os estudantes se concentrem nas decisões em termos do processo, o que implica a valorização do saber e do fazer históricos na ação cognitiva dos futuros professores, inerentes em nossa sugestão.

Acordando com esse espectro, Borba e Penteado (2017) realçam que, na Educação Matemática:

\begin{abstract}
O enfoque experimental explora ao máximo as possibilidades de rápido feedback das mídias informáticas e a facilidade de geração de inúmeros gráficos, tabelas e expressões algébricas. Por outro lado, essa prática pedagógica estimula a utilização de problemas abertos, de formulação de conjecturas em que a sistematização se dá como coroamento de um processo de investigação por parte dos estudantes (e, muitas vezes, por parte do professor). (BORBA e PENTEADO, 2017, p. 45).
\end{abstract}

Além do mais, as ferramentas do GeoGebra favoreceram a investigação histórica, pois admitiram aos estudantes de cada grupo, individual e coletivamente, averiguar etapas de uma construção geométrica já criada previamente, artifício inviável de ser realizado sem o recurso tecnológico adequado. Segundo Borba e Penteado (2017) é ainda ressaltada a ação das tecnologias digitais nas aulas: um problema que pode apontar para outro, o intercâmbio entre professores, alunos e tecnologia que suscita conjecturas e juízos matemáticos, causando desse modo uma perspectiva de experiência que muda a ordem de apresentação oral da teoria, exemplos e exercícios e proporcionando uma nova ordem regulada na investigação e, então, teorização/formalização dos conhecimentos.

Considerando o apresentado, é perceptível que o GeoGebra apoia o desenvolvimento de um estilo investigatório por parte dos estudantes, sustentando um tipo de experimentação que possibilita otimização de tempo na reconstrução de informações históricas. Vale ressaltar que, caso essas investigações históricas fossem efetivadas de outra maneira, poderiam levar bastante tempo para ser executadas, investigadas e compreendidas. Ainda aclarando, esta otimização do tempo aqui abordada 


\section{revemop}

envolve diminuição deste, mas vai além disto, isto é, não é só reduzir o tempo de cumprimento das atividades, mas aproveitá-lo da melhor maneira, utilizando o tempo obtido para averiguar e examinar relações presentes no assunto estudado.

Proporcionada a fundamentação a qual constitui base para elaborar esse trabalho, salienta-se, como mencionado antes, que o caderno de atividades sugerido se baseou na utilização da HM conectada às TDIC por meio da IM. Portanto, a próxima seção abordará os elementos históricos principais adotados na pesquisa, que se referem à civilização islâmica da idade média e exposição da biografia e trabalho matemático de Ibn Turk (século IX). É importante lembrar que desse estudo histórico foram extraídas as situações a serem averiguadas com aporte do GeoGebra as quais culminaram nas atividades do caderno proposto.

\section{3 'Abd Al-Hamid Ibn Turk e sua solução de equações quadráticas na conjuntura da matemática islâmica da idade média}

Os islâmicos colaboraram abundantemente para a produção da ciência, a partir da assimilação e aprofundamento das informações de outras culturas e também desenvolvimento de novos conhecimentos. Eles realizaram estudos em campos científicos que atualmente podemos identificar como medicina, astronomia, música, matemática, entre outros (KATZ et al., 2007).

Nessa conjuntura, a Casa da Sabedoria (ou Bayt al-H. ikma) merece destaque, por ser centro de conhecimentos científicos da Península Arábica. Nessa localidade, sábios de várias religiões e nacionalidades eram recebidos para desenvolver seus estudos intelectivos. De tal modo, foram traduzidos manuscritos de diferentes civilizações, como a grega, a babilônica e a hindu, concebendo apoio para que uma atividade científica de modo inédito fosse também lançada (BERGGREN, 1986).

A matemática foi uma área em que o império islâmico se avultou, por ser uma área com muitos empregos naquela civilização (DOAK, 1963). Sobre os atributos dessa matemática, enfatiza-se que ela era muito influenciada pela religião, pois os islâmicos confiavam estar guiados por Alá em suas aprendizagens. Além disso, tal matemática abarcava a teoria e a prática: acolhia aos anseios do dia-adia, mas ultrapassava o emprego na realidade; tinha um viés mais voltado à teorização dos conhecimentos, mas sem desconhecer o uso dos estudos dessa ciência para indigências práticas da época como comércio, agricultura, arte e arquitetura. De acordo com Katz et al (2007, p. 519, tradução nossa), "uma característica marcante da matemática islâmica, em contraste com a matemática grega, é a estreita relação entre teoria e prática". 
A álgebra foi um campo da matemática bem analisado pelos islâmicos, provavelmente pelas abertas possibilidades de aproveitamento para solução de problemas dessa civilização - complexas regras estabelecidas pelo islamismo para a repartição de heranças, o crescente comércio, a arquitetura e 0 artesanato, entre outras circunstâncias que precisavam de generalização da aritmética, por exemplo, incentivaram a produção da álgebra nesse período e região.

Vale lembrar que a álgebra citada para essa época alude à generalização dos procedimentos aritméticos e por essa razão tem intensa relação com a produção da própria aritmética. Esse evento acontecia por meio de uma fase que percebemos como inicial de seu desenvolvimento e que a historiografia antiga chama de álgebra retórica. Nessa direção existe também a álgebra geométrica, que tem elementos da generalização da aritmética, assim como dá provas geométricas dos resultados achados. Dentre os sábios islâmicos que pesquisaram álgebra em torno do século IX, estão Al-Khwarizmi ( 780- 850), Al-Mahani (820-880), Thabit Ibn Qurra (836-901), Abu-Kamil Shuja (850-930) e Al-Hamid Ibn Turk (século IX), dos quais destacamos nesse estudo o último.

Figura 1: Ibn Turk

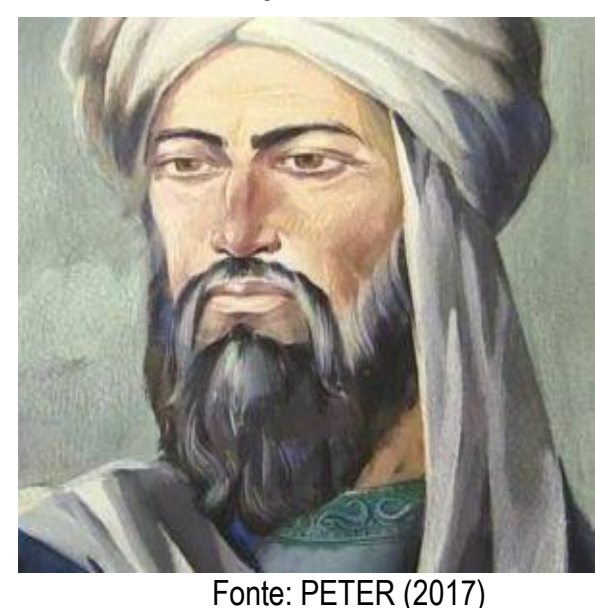

'Abd al-Hamid Ibn Turk significa servo do elogiado ('Abd al-Hamid), filho de (ibn), turco (Turk). É relevante notar que o nome dessa personalidade tem mudanças na literatura, tais como: Abd al-Hamid ibn Wasi ibn al-Turk Khutalli, Abd al-Hamid ibn Wasi ibn al-Turk al-Jili, Abu'l-Fadl, Abu Muhammad Ibn Turk al-Jili. Devido ao significado de seu nome, pode-se concluir que ele era turco ou tinha antepassados turcos. Pouco se sabe sobre sua biografia. Conforme Katz (2009, p. 274, tradução nossa), "Abd al-H. ibn Wasi ibn Turk al-Jil foi um contemporâneo de Al-Khwarizmi sobre quem muito pouco é conhecido. As fontes divergem se ibn Turk era do Irã, Afeganistão ou Síria."

O trabalho principal achado de Ibn Turk é de Sayili (1962), nomeado Logical Necessities in Mixed Equations by 'Abd al Hamid Ibn Turk and the Algebra of His Time, em português, Necessidades Lógicas 


\section{revemop}

em Equações Mistas: 'Abd al Hamid Ibn Turk e a Álgebra do Seu Tempo. Nesse artigo, a partir de Sayili (1962), foi adotado o nascimento de Ibn Turk no século IX. Segundo Doak (1963, p. 43),

o império na época [século IX] se estendia da Espanha a oeste até as fronteiras da Índia a leste, da Ásia central ao norte para o norte da África, no sul. Entrou em um período de paz e prosperidade, uma 'idade de ouro' da civilização islâmica.

A respeito dos trabalhos de Ibn Turk, conhece-se que ele elaborou um livro sobre álgebra, Kitâb Al Jabr Wa'l Muqâbala, do qual somente um capítulo, nomeado Necessidades Lógicas em Equações Mistas resistiu até a atualidade. Conforme Ibn al-Nadim (apud Saiyli), Ibn Turk foi autor de um livro sobre transações comerciais e também um livro chamado O Livro Abrangente em Aritmética. Ibn al-Qifti (apud Sayili), por sua vez, assinala que os livros elaborados por Ibn Turk são O Livro Abrangente em Aritmética, O Livro das Coisas Pouco Conhecidas em Aritmética e Aritmética, as Qualidades dos Números. Entretanto, todas essas obras se perderam.

Para Sayili (1962), o capítulo Necessidades Lógicas em Equações Mistas aborda a resolução de equações quadráticas com destaque ao raciocínio geométrico. Nele, Ibn Turk resolvia, por exemplo, casos particulares de equações polinomiais de $2^{\circ}$ grau usando a geometria. Analisando tal obra, as principais características que podem ser observadas são as seguintes: a presença da religiosidade muçulmana (de maneira especial no início do trabalho), incorporação de características da matemática grega (demonstrações por meio do raciocínio geométrico) e desenvolvimento de equações mediante uma abordagem da matemática com exemplos não aplicados no dia-a-dia da época.

No trabalho de Ibn Turk as equações quadráticas são separadas em casos, conforme o Quadro 2, sendo que, para cada caso, é dado um exemplo numérico e posteriormente, são realizadas construções geométricas com base em cada exemplo, em busca das raízes de cada equação. É relevante enfatizar que a separação em casos é feita com o desígnio de que os coeficientes $a, b$ e $c$ sejam números positivos, pois os islâmicos não trabalhavam com números negativos. Ibn Turk batiza $x^{2}$ como uma quantidade quadrada, $b x$ como número de raízes e $c$ como um certo número. 
Quadro 2: Casos de equações polinomiais do $2^{\circ}$ grau estudadas por lbn Turk

\begin{tabular}{|c|c|c|c|}
\hline Casos & $\begin{array}{c}\text { Caso enunciado retoricamente por } \\
\text { Turk }\end{array}$ & $\begin{array}{l}\text { Caso enunciado em } \\
\text { linguagem simbólica }\end{array}$ & $\begin{array}{l}\text { Exemplo dado por Turk } \\
\text { (em linguagem } \\
\text { simbólica) }\end{array}$ \\
\hline Caso 1 & $\begin{array}{c}\text { Igualdade de quantidades } \\
\text { quadradas para um número de } \\
\text { raízes }\end{array}$ & $x^{2}=b x$ & $x^{2}=3 x$ \\
\hline Caso 2 & $\begin{array}{l}\text { Igualdade de quantidades } \\
\text { quadradas e um número de raízes } \\
\text { para um certo número }\end{array}$ & $x^{2}+b x=c$ & $x^{2}+10 x=24$ \\
\hline \multirow[t]{3}{*}{ Caso 3} & \multirow{3}{*}{$\begin{array}{l}\text { Igualdade de quantidades } \\
\text { quadradas e um certo número para } \\
\text { um número de raízes }\end{array}$} & \multirow[t]{3}{*}{$x^{2}+c=b x$} & $\begin{array}{c}x^{2}+21=10 x \\
(\text { Caso 3a) }\end{array}$ \\
\hline & & & $\begin{array}{c}x^{2}+25=10 x \\
(\text { Caso } 3 b)\end{array}$ \\
\hline & & & $\begin{array}{c}x^{2}+30=10 x \\
(\text { Caso 3c) }\end{array}$ \\
\hline Caso 4 & $\begin{array}{l}\text { Igualdade de uma quantidade } \\
\text { numérica e um certo número de } \\
\text { raízes para uma quantidade } \\
\text { quadrada }\end{array}$ & $b x+c=x^{2}$ & $4 x+5=x^{2}$ \\
\hline
\end{tabular}

Fonte: MUNIZ (2020, p. 245, adaptado)

Para compreender sua proposição, será analisado aqui um dos casos indicados pelo referido islâmico como exibido no Quadro 2. Trata-se do caso 4 exemplificado pela equação $4 x+5=$ $x^{2}$. Sobre ele Ibn Turk (apud Sayili) coloca que

O caso da igualdade de uma quantidade numérica e um certo número de raízes para uma quantidade quadrada. Assim, quando dizemos que quatro raízes e cinco dirhams são iguais a uma quantidade quadrada, definimos a quantidade quadrada igual a uma figura quadrilateral plana de lados iguais e ângulos retos. Deixe esta ser a superfície $A D$. Cada um dos seus lados é a raiz da quantidade quadrada. Dentro dele desenhamos a linha $H Z$ paralela às linhas $A B e$ $C D$, e definimos a superfície $A Z$ igual a cinco. A superfície restante HD é, portanto, igual a quatro raízes. Como a linha $C D$ é a raiz da quantidade quadrada e a superfície HD é igual a quatro raízes, a linha $\mathrm{HC}$ passa a ser igual a quatro. No ponto $\mathrm{Q}$ nós dividimos a linha $\mathrm{HC}$ em duas partes iguais, e desenhamos a linha QT perpendicular a ela e igual a cada uma das duas linhas $\mathrm{HQ}$ e QC. Seu comprimento é assim igual a dois. Nós completamos o KQ quadrilateral, que é igual a quatro. Em seguida, estendemos a linha $Q T$ até o ponto $L$ e definimos a linha $T L$ igual a cada uma das linhas AH e BZ. Nós desenhamos a linha LM em ângulos retos para a linha $Q L$. A linha $A Q$ é assim igual à linha MA. A linha $Q C$ é, portanto, igual a MB. Mas a linha $Q C$ também é igual à linha $L N$. A linha $L N$ é assim igual a MB. $E$ cada um de KN e TL é igual a cada um dos MN e BZ. O MZ quadrilateral é, portanto, igual ao KL quadrilateral. Em nossa construção, o quadrilátero AN é contíguo a ambos os quadriláteros. Os quadriláteros AN e BN juntos, portanto, são iguais aos quadriláteros AN e NT. Mas os quadriláteros AN e JMB juntos são iguais a cinco. Os quadriláteros AN e NT juntos são iguais a cinco. Mas o KQ quadrilateral é igual a quatro. $\mathrm{O}$ quadrilátero $\mathrm{AL}$ tem, portanto, o valor nove. Cada um dos seus lados é a 
sua raiz. Assim, a linha $A Q$ é igual a três. Agora, a linha $Q C$ era igual a dois. $A$ linha inteira $A C$ é portanto igual a cinco e esta é a raiz da quantidade quadrada. (TURK apud SAYILI, 1962, p. 48 , tradução nossa).

A construção preconizada por Ibn Turk mediante processos retóricos no texto segue, deste modo, os passos: primeiramente, é formada "uma figura quadrilateral plana de lados iguais e ângulos retos", ou seja, um quadrado, que representa a quantidade quadrada $\left(x^{2}\right)$. Portanto, cada lado do quadrado corresponde a $x$, a raiz da equação. Essa é a denominada superfície AD.

Figura 2: Superfície AD

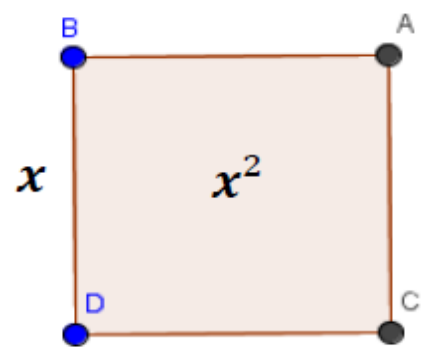

Fonte: Construído pelas autoras com auxílio do GeoGebra

Interno à superfície $A D$, é traçado o segmento $H Z$, paralelo aos segmentos $A B$ e $C D$. Ibn Turk determina a área da superfície $A Z$ (retângulo BAHZ) como sendo cinco. A superfície remanescente HD (retângulo ZHCD) é, assim, igual a quatro raízes. Isso é esclarecido pela equação que está sendo resolvida geometricamente $\left(4 x+5=x^{2}\right)$. Ela assinala que a área do quadrado (ABDC) equivale a quatro raízes $(4 x)$ mais cinco (5). O sapiente conclui também que o segmento HC corresponde a quatro, pois a área do retângulo ZHCD vale 4 raízes $(4 x)$ e o segmento CD é igual a $x$.

Figura 3: Construção do segmento HZ

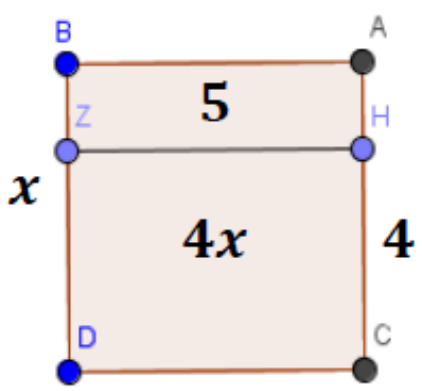

Fonte: Construído pelas autoras com auxílio do GeoGebra

A etapa seguinte versa em obter o ponto $Q$, ponto médio de HC. Depois, é determinado 0 segmento QT, perpendicular à $\mathrm{HC}$ e de mesmo comprimento da medida de $H Q$ e $Q C$, isto é, duas unidades de comprimento. 
Figura 4: Construção dos segmentos $\mathrm{HQ}, \mathrm{QC}$ e TQ

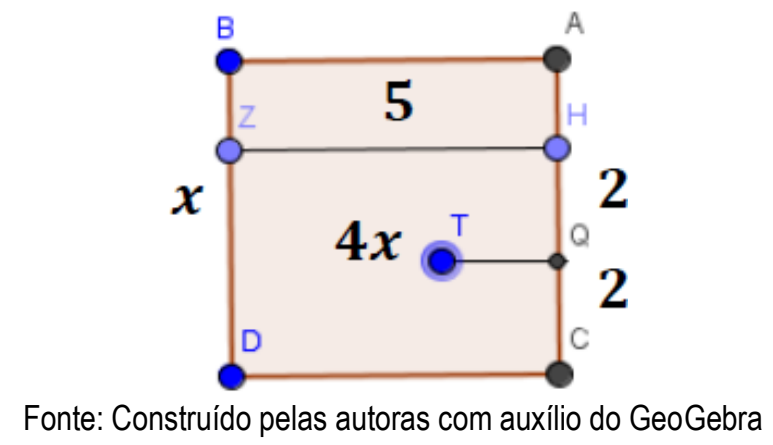

Completa-se então, a partir do segmento QT, o quadrado KHQT, que tem área quatro, visto que seus lados medem duas unidades cada.

Figura 5: Construção do quadrado KHQT

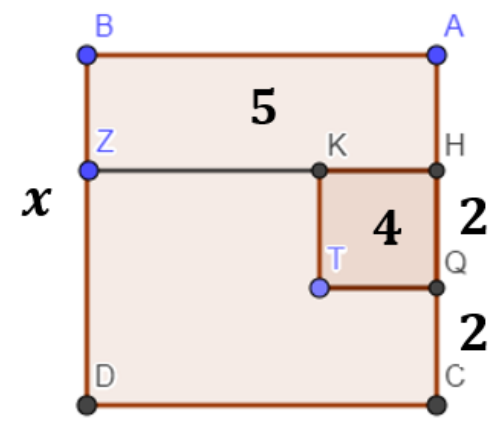

Fonte: Construído pelas autoras com auxílio do GeoGebra

Nessa fase, o segmento QT será prolongado até o ponto L, e o novo segmento TL necessitará ter medida igual aos segmentos AH e BZ. É relevante enfatizar que, com a constituição do segmento TL, também geramos o segmento QL, que tem medida igual à QT + TL. Finalmente, o último passo dessa construção geométrica é elaborar o segmento LM. Tal segmento deve ser construído de forma a obter ângulos retos com o segmento QL.

Figura 6: Construção geométrica que representa a equação $4 x+5=x^{2}$

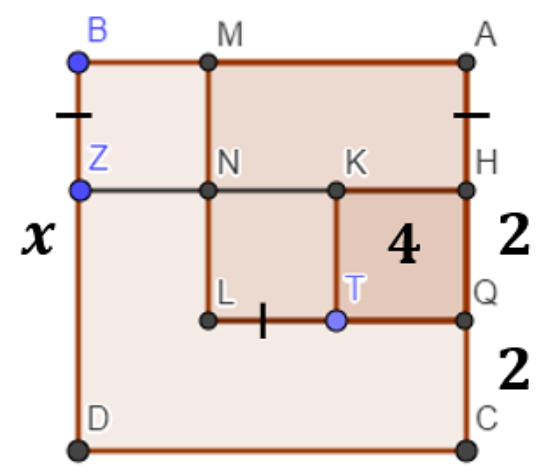

Fonte: Construído pelas autoras com auxílio do GeoGebra 


\section{revemop}

Finalizada a constituição geométrica, Ibn Turk observa que, por construção, o segmento $A Q$ tem medida igual ao segmento MA. O segmento $Q C$ é, deste modo, de igual medida de MB. O segmento $Q C$, entretanto, tem a mesma medida do segmento LN. Portanto, o segmento LN tem a mesma medida de MB. É possível observar também que KN e TL correspondem às medidas dos segmentos MN e BZ. $O$ retângulo BMNZ, assim, tem mesma área do retângulo NKTL.

Na construção, o quadrilátero AHNM é contíguo aos dois quadriláteros BMNZ e NKTL. Logo, os quadriláteros AHNM e BMNZ juntos têm a mesma área dos quadriláteros AHNM e NKTL. Mas a área dos quadriláteros AHNM e BMNZ juntos vale cinco unidades de área. Isto é, a área dos quadriláteros AHNM e NKTL juntos é a mesma, ou seja, cinco unidades de área. Porém o quadrado KHQT tem área igual a quatro. $O$ quadrilátero $A M L Q$ possui, assim, área equivalente a nove. De tal modo, o segmento $A Q$ é igual a três unidades de comprimento. É sabido que cada um dos lados do quadrado ABDC é a raiz da equação $4 x+5=x^{2}$ e que o segmento $Q C$ tem medida correspondente a duas unidades de comprimento. Como $A C=A Q+Q C$, incluímos que $A C=3+2=5$. Deste modo, obtém-se o resultado de que a raiz da equação $4 x+5=x^{2}$ é de 5 unidades.

Ponderando o que foi colocado até esse momento, a seção adiante traz uma abordagem com destaque no caderno de atividades, avultando pontos do processo de preparação e posterior emprego desse na licenciatura em matemática.

\section{0 caderno de atividades}

Levando em conta o que foi colocado até aqui, um caderno de atividades foi produzido com apoio na conexão entre história da matemática e o GeoGebra mediante investigação matemática. 0 produto educacional elaborado tem o desígnio de possibilitar aos licenciandos em matemática uma outra maneira de compreender o conteúdo de equação quadrática, bem como, expandir a formação docente referente à história da matemática, tecnologias digitais da informação e comunicação e investigação matemática como propostas didáticas.

Figura 7: Capa do caderno de atividades 


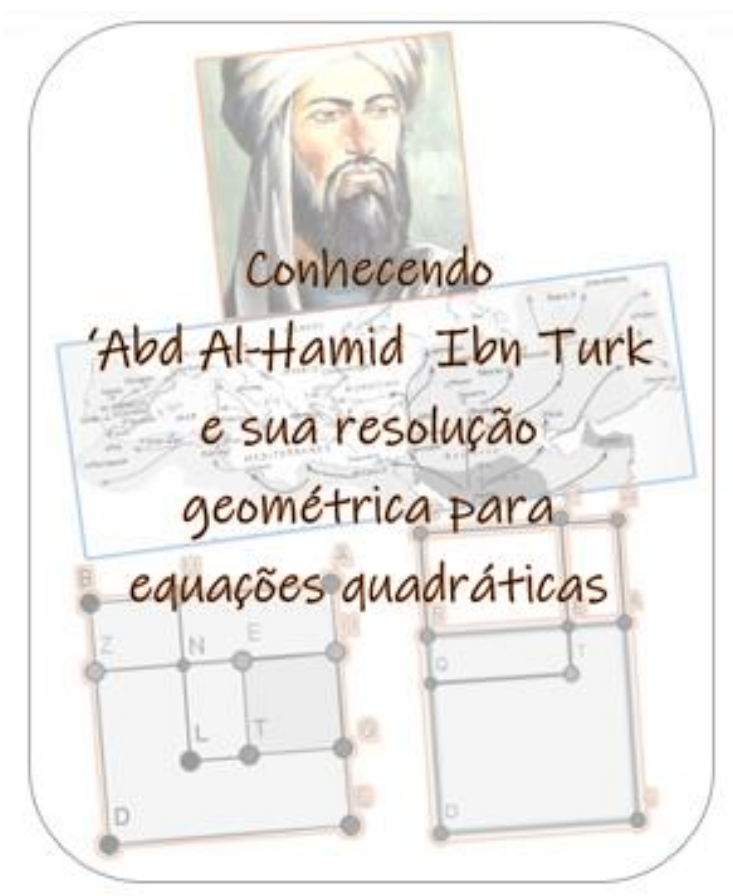

Fonte: MUNIZ (2020, p. 206)

Após o estudo bibliográfico desenvolvido, uma primeira ação foi o desígnio de quais casos de resolução geométrica de equações quadráticas presentes na obra de lbn Turk, seriam abordados no caderno de atividades, considerando que usar todos os 4 casos elaborados por Ibn Turk, sendo um dos casos dividido ainda em três outros, comporia um produto educacional extenso. De tal modo, selecionamos dois casos a serem usados no produto educacional: o caso em que $\Delta<0$ (Um dos casos estudados por Ibn Turk recai na condição que hoje percebemos como $\Delta<0$, apesar do conceito de discriminante não ser existente na época dele) e o caso de equações do tipo $x^{2}=b x+c$.

Da investigação histórica ainda foram tiradas situações problemas (relacionadas a necessidades do contexto islâmico da idade média e que também podem ser utilizadas em situações atuais) que recaiam em equações quadráticas, particularmente as que se enquadravam nos casos selecionados para estarem presentes nas atividades do produto educacional. Desse modo, as equações mencionadas por Ibn Turk em seu estudo, e ainda equações trazidas por outros islâmicos medievais como AlKhwarismi bem como o contexto islâmico de mesma época serviram de base para preparação dos quatro problemas que estão no caderno de atividades. Tendo em vista a falta de material relativo às questões que tratam de situações práticas daquele período desenvolvidas por lbn Turk, optou-se por usar todas essas informações como base na proposição de problemas que recaíssem nos casos aludidos antes, averiguados por esse estudioso.

Nas atividades, os textos exploratórios e situações investigativas postos, por sua vez, foram arquitetados num ensaio de aproximação de historiografia atualizada, no sentido de fazer os licenciandos 


\section{revemop}

pensarem sobre as ideias matemáticas respeitando os diferentes contextos (islâmico medieval e atual) relativos ao estudo de equações quadráticas. Cabe destacar, nessa direção, que recentemente há duas vertentes historiográficas que surgem na literatura: a historiografia tradicional e historiografia atualizada. Conforme Saito e Roque (apud MOREY e GOMES, 2018), a vertente atualizada é a que aprecia os contextos de elaboração, mutação, transmissão e disseminação do conhecimento matemático em díspares épocas e culturas, enquanto que a perspectiva historiográfica tradicional realça a coerência interior do discurso matemático, tendo como ponto de partida o que nós percebemos por matemática hoje em dia numa perspectiva linear e progressista.

Os aspectos aludidos antes nos induzem a estrutura do produto educacional, delineada a seguir. O caderno de atividades conta com uma atividade introdutória (texto e questionamentos envolvendo contextualização histórica da civilização islâmica, desde seu surgimento até o período de empenho para o trabalho, contendo uma visão geral dessa sociedade) e outra, a Atividade I, que almeja familiarizar os alunos com a álgebra geométrica da civilização islâmica medieval, mas não aborda nenhum caso específico de equação quadrática analisado por lbn Turk.

Na composição do caderno de atividades temos ainda a Atividade II e a Atividade III, sendo que as duas tratam da resolução geométrica de equações quadráticas, abarcando o consórcio entre história da matemática e GeoGebra via investigação matemática, tomando como apoio o capítulo Logical Necessities in Mixed Equations by 'Abd al Hamid Ibn Turk and the Algebra of His Time da obra Kitâb Al Jabr Wa'l Muqâbala de Ibn Turk, que traz quatro casos como alternativa de solução de tais equações e dos quais propusemos dois como referência, sendo um abordado na Atividade II e outro na Atividade III. Cada atividade (com exceção da introdutória, que tem apenas o Texto 01 e questionamentos iniciais) é composta pelos elementos:

- Informações Gerais - Quadro presente no início de cada atividade, informando conhecimentos prévios que 0 aluno deve ter para realizar a atividade e recursos necessários para execução da mesma.

- Seção Texto e Contexto - Texto que contém informações gerais sobre o contexto da civilização islâmica medieval, com foco para a matemática desenvolvida nesse período. Ao final da seção, é apresentado um problema, a ser investigado pelos alunos, envolvendo equação quadrática e 0 método de lbn Turk.

- Seção Estudando o Texto - Traz questionamentos que objetivam aprofundamento dos conhecimentos apresentados na seção Texto e Contexto. 
- Seção Construindo e Explorando - Apresenta questionamentos que promovem construções no software GeoGebra, assim como realização de investigação matemática dessas mesmas construções feitas pelos estudantes. Momento de formular conjecturas e fazer testes com as mesmas.

- Seção Ampliando os Horizontes - Aborda questões que visam dar continuidade ao processo de investigação matemática iniciada pelos alunos na seção anterior. Validam-se e/ou refinam-se as conclusões obtidas.

- Seção Registrando Entendimentos - Momento de socialização/avaliação das etapas até então concluídas das atividades.

Figura 8: Sumário do produto educacional

\begin{tabular}{|c|}
\hline SUMÁRIO \\
\hline APRESENTAÇĀO.......................... \\
\hline ORIENTAÇÖES GERAIS PARA O PROFESSOR......... \\
\hline OBJETIVOS DO CADERNO DE ATIVIDADES \\
\hline ESTRUTURA DO CADERNO E DAS ATIVIDADES \\
\hline SUGESTÖES DE MATERIAIS COMPLEMENTARES.................................... \\
\hline EXPECTATIVAS DE RESPOSTA \\
\hline SUGESTĀO DE CRONOGRAMA PARA APLICAÇĀO DAS ATIVIDADES.......22 \\
\hline Atividade Introdutória (Ả guisa de introdução) \\
\hline Questionamentos iniciais............................................ \\
\hline Atividade I - Refletindo sobre a álgebra geométrica..... \\
\hline 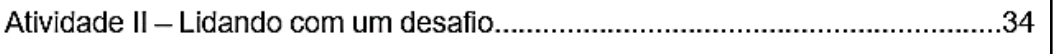 \\
\hline Atividade III - A questão do comércio........ \\
\hline 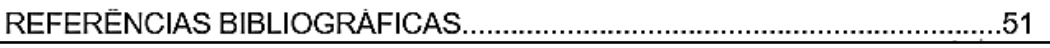 \\
\hline
\end{tabular}

Fonte: MUNIZ (2020, p. 207)

A aplicação do caderno ocorreu no semestre 2019.2 em uma turma de Didática da Matemática I, oferecida ao curso de licenciatura em matemática da Universidade Federal do Rio Grande do Norte (UFRN), que computava 39 alunos matriculados, sendo que em média 35 participavam das aulas regularmente. Os encontros para concretização das atividades ocorreram no Laboratório de Micros localizado na sala H4 do setor de aulas III da UFRN. Tal espaço tem 42 computadores, todos funcionando normalmente, a maioria com acesso à Internet e o software GeoGebra alojado. No primeiro encontro, os estudantes foram encaminhados a formar duplas para prática de todas as atividades. 
Figura 9: Alunos realizando atividades do produto educacional

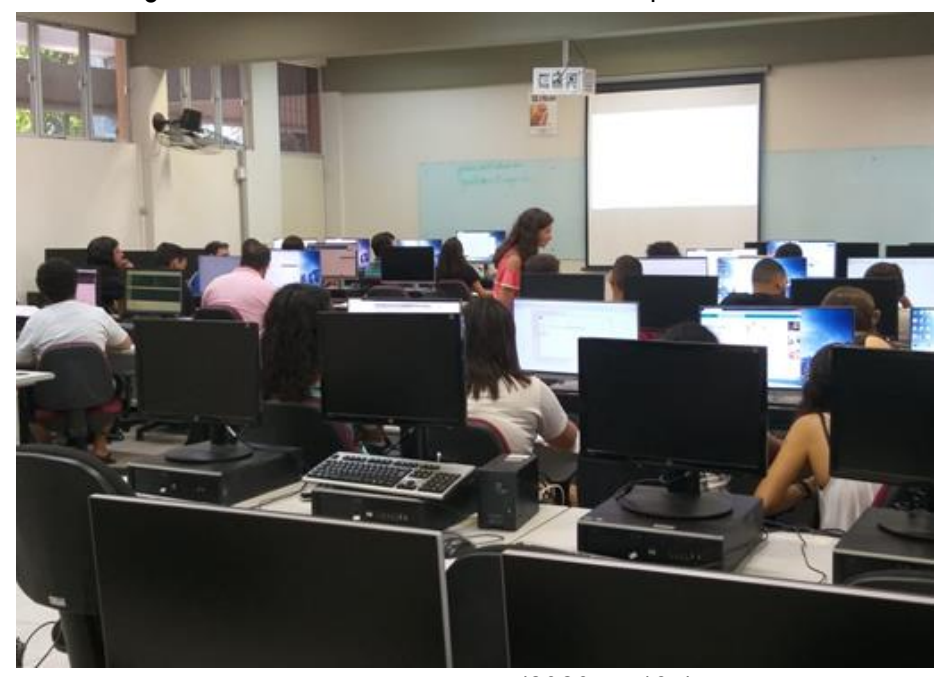

Fonte: MUNIZ (2020, p. 137)

As atividades foram aplicadas em três encontros, perfazendo dez aulas de 50 minutos cada. No cronograma de aplicação, no entanto, estavam previstas oito aulas de 50 minutos, contudo em virtude de alguns imprevistos e ao caráter de determinadas atividades houve a necessidade de mais duas aulas para completar a aplicação. Enfatiza-se que o produto educacional foi aplicado como uma atividade regular da disciplina, visto que consta na ementa da mesma 0 estudo e análise das tendências em Educação Matemática como história da matemática, tecnologias e investigação matemática. No encontro inicial, foi efetivada a explanação inicial sobre a pesquisa (incluindo aplicação de instrumento como carta de direitos e questionário inicial) e o produto educacional, bem como, aplicação da Atividade I e parte da Atividade II. No segundo encontro, foi finalizada a Atividade II e realizada parte da Atividade III. Por fim, no terceiro encontro, foi concluída a Atividade III e aplicado o questionário final. Como mencionado antes, ao longo da aplicação do produto educacional a coleta de dados foi feita a partir de questionários inicial e final, registros escritos e virtuais de alunos, diário de campo, foto e filmagem.

Pela análise desses instrumentos, relativo à parte introdutória do caderno de atividades, foi perceptível que os alunos evidenciaram compreensão relativa ao Texto 1, que tratava de aspectos gerais da civilização islâmica, tais como: surgimento, contexto político, econômico, religioso e científico. Esse texto despertou ainda curiosidade nos licenciandos, de modo que eles se interessavam em saber mais detalhes sobre a civilização islâmica. Além disso foi feita uma discussão, bastante produtiva e com extensa participação dos estudantes, acerca do que havia sido estudado até então. Assim, essa parte da atividade serviu de apoio para o desenvolvimento das outras tarefas e conduziu os professores em formação a um diálogo dinâmico com os aspectos transdisciplinares da matemática investigada. (MENDES, FOSSA e VALDÉS, 2006). 
A atividade I proporciona um texto que penetra na matemática islâmica da idade média, assinalando suas características basilares e dando evidência para a álgebra de tal civilização. É tratada a álgebra geométrica, sendo desejado que o aluno investigue a solução de uma situação inspirada no contexto islâmico (problema sobre herança) usando equações quadráticas e ainda reflita, com alicerce no texto, sobre como os estudiosos islâmicos averiguavam tal problema empregando o raciocínio geométrico. Essa atividade possibilitou que os estudantes se colocassem no lugar dos estudiosos islâmicos do século IX, desenvolvessem empatia pela história da população e se interrogassem acerca da matemática, de maneira especial a álgebra, produzida por essa civilização.

A atividade II exibe o estudioso Turk, abarcando notas biográficas e considerações relevantes sobre seu trabalho com álgebra geométrica à luz de sua época, tais como a divisão em casos, a terminologia específica de cada caso, entre outras. O texto é encerrado com a apreciação de um problema, também inspirado no contexto islâmico medieval, e o estudante é chamado a examinar tal problema do ponto de vista da álgebra atualizada e ainda sob a perspectiva da álgebra geométrica de Turk, constituindo elos entre os dois enfoques.

Figura 10: Parcial da Atividade II do produto

$\begin{gathered}\text { PROBLEMA } 3 \\ \text { Um terço de uma quantidade é multiplicada por sua quarta parte, sendo } \\ \text { igual à quantidade diminuida de vinte e quatro dirhams. Qual a } \\ \text { quantidade? }\end{gathered}$
ESTUDANDo o TEXTo
1) Retome o Texto 02 (Atividade I) e encontre quais outros estudiosos,
contemporâneos de Ibn Turk, trabalhavam com álgebra em uma perspectiva
geométrica.
2) Pensando na História da Matemática, quais as possiveis justificativas para
que, na historiografia, exista uma indefinição acerca da autoria do primeiro livro
de álgebra? Liste duas delas.
3) Retome o Quadro 01 , do Texto 03 , e complete-o.
4) Resolva o problema 3 .
5) Qual caso geral de equação polinomial de $2^{\circ}$ grau, dentre os propostos por
Ibn Turk e apresentados no Quadro 01, representa a equação elaborada por
você para modelar o problema 3 acima? Indique o número e a representação
simbólica.

Fonte: MUNIZ (2020, p. 246)

Após a Seção Estudando o Texto, apresentada na Figura 10, há a Seção Construindo e Explorando, em que os estudantes teriam de construir a figura geométrica organizada no século IX por Ibn Turk e explorar essa construção. Assim, os licenciandos foram guiados por uma tabela a investigar a solução de equações do tipo $x^{2}+c=b x$ quando $\Delta<0$. Na primeira coluna dessa tabela, está 
presente cada passo preconizado por Ibn Turk e enunciado retoricamente, enquanto na segunda coluna estão os passos (correspondentes) a serem dados no GeoGebra, além de questionamentos ao longo da construção que buscam orientar/impulsionar investigações.

Figura 11: Parte da Seção Construindo e Explorando, da Atividade II

\begin{tabular}{|c|c|}
\hline $\begin{array}{l}\text { Nós dividimos a linha } \\
\text { ZD em duas partes } \\
\text { iguais no ponto Q. O } \\
\text { ponto Q, que é o } \\
\text { ponto médio, cairá na } \\
\text { linha ZB ou na linha } \\
\text { BD. Deixe o ponto Q } \\
\text { cair dentro da seção } \\
\text { BD. }\end{array}$ & $\begin{array}{l}\text { c) Marque o ponto médio do segmento ZD. Para isso, } \\
\text { utilizaremos a função Ponto médio ou centro, localizado } \\
\text { na aba Ponto e clicando respectivamente em Z e D. } \\
\text { - Com o botão direito do mouse, clique sobre esse } \\
\text { ponto obtido e usando a opção Renomear, o } \\
\text { renomeie para Q. } \\
\text { ATENÇÃO: o ponto Q deve estar situado no segmento BD. }\end{array}$ \\
\hline- & $\begin{array}{l}\text { Questionamentos } \\
\text { - Considerando a representação simbólica da } \\
\text { equação do problema 3, qual a medida do segmento } \\
\text { DZ? Porque? } \\
\text { - Ao marcar o ponto médio do segmento DZ, dois } \\
\text { novos segmentos apareceram. Quais são eles e } \\
\text { quais suas medidas, considerando a representação } \\
\text { simbólica da equação do problema 3? }\end{array}$ \\
\hline
\end{tabular}

Fonte: MUNIZ (2020, p. 248)

No fim da Seção Construindo e Explorando, como citado, existe a seção Ampliando os Horizontes, que trata de questões que continuam o procedimento de investigação matemática começada pelos estudantes na seção antecedente. Dessa forma, é desejado que os estudantes validem e/ou refinem as conclusões alcançadas.

Figura 12: Trecho da Atividade II em que aparece a Seção Ampliando os Horizontes

AMPLIANDO OS HORIZONTES
1) Ibn Turk chegou à uma conclusão acerca do tipo de equação do caso 3, e
assim ele enuncia o caso 3c (vide Quadro 01). Ele enuncia tal conclusão como
Há a necessidade lógica de impossibilidade neste tipo de equação
quando a quantidade numérica que está com a quantidade quadrada é
maior que a metade do número de raizes multiplicada por seu igual.
(TURK apud SAYILI, 1962, p. 20).
Traduza essa conclusão para linguagem simbólica e explique-a considerando a
construção feita no Geogebra.
2) O que você pensa sobre a inclusão de raciocínio geométrico na resolução de
equações quadráticas para estudantes da Educação Básica? Como isso poderia
ser feito, com base nessa atividade?

Fonte: MUNIZ (2020, p. 250)

Nessa atividade os alunos apresentaram mais dificuldades por múltiplos agentes, como não familiarização com o procedimento investigativo e a álgebra retórica. 0 alvo basilar dessa atividade era aclarar a solução geométrica de Turk para a equação do tipo $x^{2}+c=b x$ quando $\Delta<0$, sendo que os 
licenciandos obtiveram tal feito, com ajuda da pesquisadora. $O$ desenvolvimento de tal atividade foi fundamental para a maturação dos licenciandos, pois, ao passo que analisavam tal tarefa, foram compreendendo mais sobre 0 andamento investigativo, o levantamento e testes de conjecturas, as ferramentas do software GeoGebra, o trabalho em equipe, a argumentação e validação das ideias matemáticas.

Já a Atividade III ocasionou um aspecto diferente de investigação matemática, quando comparada à Atividade II: ao invés de construir e interpretar a construção geométrica, os discentes deveriam avaliar uma construção geométrica já executada, para procurarem elucidar a resolução geométrica de Ibn Turk para equações do caso $b x+c=x^{2}$. O problema alvitrado, que recai em uma equação desse caso, é o indicado na Figura 13.

Figura 13: Problema que recaí em uma equação do caso $b x+c=x^{2}$

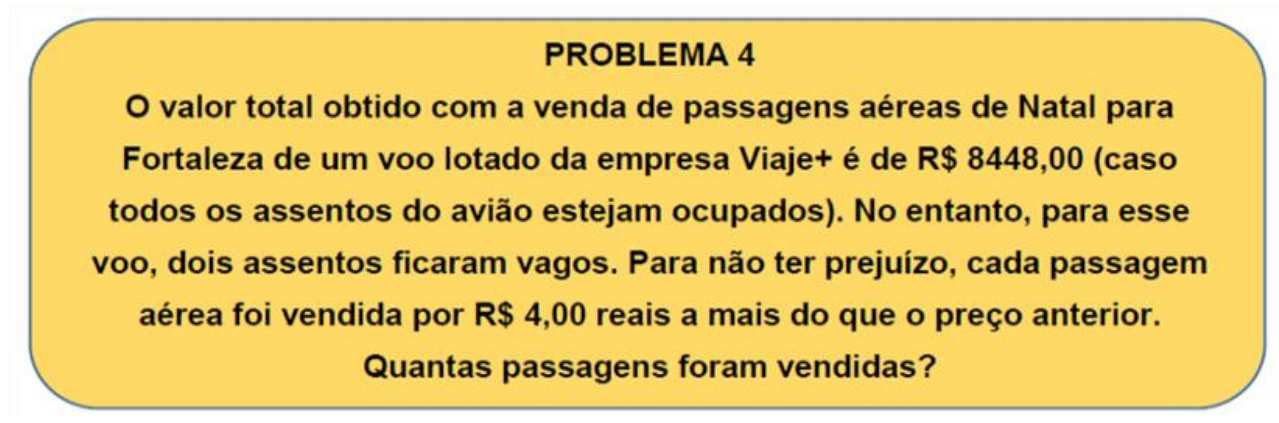

Fonte: MUNIZ (2020, p. 253)

Novamente se avultam as funções do software GeoGebra, que proporcionou a efetivação dessa atividade mediante, sobretudo, à ferramenta Protocolo de Construção. Essa ferramenta admite que cada passo de uma construção já formada, possa ser visto e reproduzido como num vídeo, podendo também, realizar pausas e retornos aos pontos não entendidos. Provavelmente tal atividade seria inexequível, caso não fosse usado esse tipo de recurso, considerando que o dinamismo aludido foi fundamental para a investigação.

Figura 14: Passo final da primeira parte da investigação, em que aluno encontra a raiz da equação que modela o Problema 4, a partir da solução geométrica de Ibn Turk

- Salrendo que a área de $A Q L M=4225$, temos que $A Q=65$. Como en eontrado anterion mente, $Q C=1$. Logo, $A C=X=66$.

Fonte: Acervo das autoras

Os licenciandos, nessa atividade, (re)descobriram o modo de obter a raiz positiva de uma equação quadrática geometricamente conforme Ibn Turk, resolução estimada impraticável por muitos, ponderando que a Atividade II oferecia um caso em que a construção geométrica recaía em um absurdo, 
e que o sábio não achou a solução. Já acostumados com a abordagem em sala de aula, de modo quase autônomo, os estudantes conseguiram deliberar sobre as indagações indicadas nessa atividade, fazendo ponderações mais rígidas do ponto de vista matemático, quando contrastadas com as atividades antecedentes. Isso porque, nas atividades I e II, as respostas dos alunos, bem como seus esclarecimentos, eram abreviadas e com articulação insuficiente, algumas vezes, do ponto de vista da linguagem matemática. Fossa, Mendes e Valdés (2006) argumentam defendendo a efetivação de tarefas envolvendo história da matemática como modo de propiciar ao discente a satisfação de praticar a formalização matemática com significado.

\section{Considerações finais}

Ao aplicar o produto foi possivel perceber que as tecnologias ajudam no procedimento de (re)construção de descobertas matemáticas ao passo que os professores em formação otimizam o tempo para organizar construções, restando deste modo maior tempo para realizar investigações guiadas nos problemas da história da matemática. Assim, os licenciandos puderam, ao longo do andamento investigativo dos problemas históricos, com base no GeoGebra, (re)descobrir e analisar a maneira pela qual Ibn Turk lidou com equações quadráticas no século IX. Para tanto, foram levados a explorar os recursos dinâmicos do GeoGebra de forma a buscar saber o que não conheciam, familiarizando-se com o tema, levantando conjecturas, testando-as e procurando validá-las de modo a socializar as conclusões e fechar o processo investigativo norteado por atividades compostas por textos históricos exploratórios e análise de problemas via TDIC.

Ademais, foi constatado que diversos dos argumentos favoráveis exibidos relativos a história da matemática coligada às tecnologias digitais da informação e comunicação via investigação matemática puderam ser observados, tais como (re)conhecimento da história da matemática como fonte de problemas atraentes a serem investigados, a matemática como produto social, cultural e científico da humanidade, 0 estabelecimento de relações e reflexões entre o desenvolvimento da matemática e 0 contexto histórico das sociedades, o maior empenho em examinar os conceitos matemáticos tratados e a participação atuante dos estudantes na construção/desenvolvimento do conhecimento. Destaca-se ainda que, mediante a apreciação dos registros escritos e virtuais de alunos, diário de campo, fotos, filmagem e de questionários inicial e final, foi possível concluir que, com a consumação das atividades anteriores, os estudantes ficaram ativamente empenhados com a matemática e otimizaram uma apreciação de procedimentos matemáticos, abarcando abstração e demonstração (essas aconteceram na aliança entre os ensaios manipulativos feitos por meio da interação aluno-software num coletivo pensante, segundo Borba e Penteado (2017), e os desafios e problemas recapturados da história ao 
poder de generalização que os exercícios formais podem ter). Pondera-se, assim, que a melhora da bagagem intelectiva dos estudantes aconteceu do decorrer da efetivação das atividades, de maneira especial, alusivas a matemática, sua história e uso pedagógico.

Portanto, apoiados no software GeoGebra, os licenciandos (re)descobriram e avaliaram a maneira pela qual Ibn Turk (século IX) trabalhou com as equações quadráticas. Através da investigação matemática, procuramos que os professores em formação realizassem a leitura e discussão dos aspectos matemáticos envolvidos nas informações históricas para que eles conseguissem (re)descobrir um método histórico de solução de equações quadráticas, bem como sua validação matemática. No encerramento desse procedimento ativo-reflexivo, almejou-se que os envolvidos conseguissem situar relações entre a solução geométrica e a solução algébrica para essas equações, o que realmente foi percebido e, além disso, foi notado que eles se apropriaram desse método realizando reflexões/comparações com o modo de solução já conhecido por eles, assinalando, até mesmo, outros caminhos e interrogando possibilidades e limites tendo em vista o contexto do século IX e atual. Percebemos ainda que a aplicação dessas atividades mobilizou diversos conhecimentos matemáticos (nesse caso, geométricos e algébricos), como observado por outros trabalhos desenvolvidos na perspectiva de resolução de problemas/atividades históricos, como por exemplo em Pontes et al (2021).

Tendo em vista o que foi colocado, a questão-foco sugerida ao início desse estudo, a saber: De que maneira seria possível aliar HM e TDIC via IM para o estudo e/ou ensino de álgebra geométrica na licenciatura em matemática? foi respondida no decorrer desse artigo, revelando que a recuperação didática do capítulo Necessidades Lógicas em Equações Mistas da obra intitulada Kitâb Al Jabr Wa'l Muqâbala, do islâmico Ibn Turk, delineada no formato de um caderno de atividades que alvitra a efetivação de investigações históricas realizadas com o apoio do software GeoGebra contribuiu para a reflexão e a socialização de conhecimento dos licenciandos e, consequentemente, sua formação em aspectos matemáticos e pedagógicos. Destaca-se que essa pesquisa qualitativa resultou em um produto educacional elaborado com base no divulgado, disponível livremente em Muniz (2020). Nessa ótica, o mesmo consta ainda de recomendações para uso e materiais de apoio. Vale ressaltar ainda que o estudo tem limites quanto, por exemplo, à abordagem de todos os casos tratados por Ibn Turk já que no produto elaborado até o momento, não foram tratadas todas as possibilidades vislumbradas pelo referido islâmico, contudo, como proposição de futuros estudos, pretende-se explorar os outros casos de equação quadrática estudados por 'Abd Al-Hamid ibn Turk em novas atividades para utilização em sala de aula.

\section{Referências}

BERGGREN, J. L. Episodes in the mathematics of medieval Islam. New York: Springer, 1986. 
BOGDAN, Robert C.; BIKLEN, Knopp Sari. Investigação qualitativa em Educação. Portugal: Porto Editora, 1994.

BORBA, Marcelo de Carvalho; PENTEADO, Miryan Godoy. Informática e Educação Matemática. 5 ed. Belo Horizonte: Autêntica, 2017.

DOAK, Robin Santos. Empire of the Islamic world. Rev. ed. p. cm. (Great empires of the past). New York: Chelsea House Publications, 1963.

FAUVEL, John; MAANEN, Jan Van. (Org.). History in Mathematics Education: the ICMI study. Dordrecht: Kluwer Academic Publishers, 2000.

FOSSA, John Andrew; MENDES, Iran Abreu; VALDÉS, Juan E. Nápoles. A história como um agente de cognição na Educação Matemática. Porto Alegre: Sulina, 2006.

KATZ, Victor J. et al. The mathematics of Egypt, Mesopotamia, China, India, and Islam: a sourcebook. New Jersey: Princeton University Press, 2007.

KATZ, Victor J. A History of Mathematics - An Introduction. 3. ed. Boston: Addison-Wesley, 2009.

MENDES, Iran Abreu. Matemática e investigação em sala de aula: tecendo redes cognitivas na aprendizagem. Natal: Flecha do Tempo, 2006.

MIGUEL, Antonio; MIORIM, Maria Ângela. História na Educação Matemática: propostas e desafios. 2. ed. Belo Horizonte: Autêntica Editora, 2011.

MOREY, Bernadete Barbosa; GOMES, Severino Carlos. Matemática mesopotâmica: história para o professor de matemática. Revista REMATEC, Natal, v. 13, n. 27, p. 6-23, jan./abr. 2018.

MUNIZ, Jéssica Targino. Soluções de equações quadráticas por 'Abd al Hamid Ibn Turk na formação inicial do professor de matemática: uma perspectiva orientada pela história da matemática. 2020. $276 f$. Dissertação (Mestrado Profissional em Ensino de Ciências Naturais e Matemática) - Centro de Ciências Exatas e da Terra, Universidade Federal do Rio Grande do Norte, Natal, 2020.

PETER, Kivanç. Abdulhamid ibn Turk. Disponível em: <https://anadolubilim.com/abdulhamid-lbn-turkhayati/> Acesso em 06 maio 2019.

PONTE, João Pedro da; BROCARDO, Joana; OLIVEIRA, Hélia. Investigações matemáticas na sala de aula. 3 ed. Belo Horizonte: Autêntica Editora, 2013.

PONTES, L. M.; BATISTA, A. N. DE S.; PEREIRA, A. C. C. A inserção de textos originais na disciplina de História da Matemática a partir de um problema do documento Sea Island Mathematical Manual. Revemop, v. 3, p. e202101, 1 jan. 2021.

POLIT, Denise F.; BECK, Cheryl Tatano; HUNGLER, Bernadette P. Fundamentos de pesquisa em enfermagem: métodos, avaliação e utilização. Tradução de Ana Thorell. 5. ed. Porto Alegre: Artmed, 2004.

ROQUE, Tatiana. História da Matemática: uma visão crítica, desfazendo mitos e lendas. Rio de Janeiro: Zahar, 2012. 
SAYILI, Aydin. Logical Necessities in Mixed Equations by 'Abd al Hamid Ibn Turk and the Algebra of His Time. Ankara: Turk Tarih Kurumu Basimevi, 1962. Disponivel em:

$<$ <ttp://www.muslimheritage.com/article/logical-necessities-mixed-equations-abd-al-ham\%C3\%AEd-lbnturk-and-algebra-his-time/> Acesso em 29 maio 2019.

THIOLLENT, Michel. Metodologia da pesquisa-ação. São Paulo: Cortez \& Autores Associados, 1988.

TRIPP, David. Pesquisa-ação: uma introdução metodológica. Educação e Pesquisa, São Paulo, v. 31, n. 3, p. 443-466, set./dez. 2005. 